\title{
O uso das tecnologias como ferramenta para a formação continuada e autoformação docente
}

\author{
Giovanni Bohm Machado' (D) \\ Juliana Aquino Machado" (D) \\ Leandro Krug Wives' (D) \\ Gilberto Ferreira da Silva" (D)
}

RESUMO

A formação docente é um processo que ocorre durante toda a vida e inclui as experiências de aprendizagem profissional que contribuem para a qualidade da educação. A formação continuada de professores, contemplando processos autoformativos e colaborativos, encontra nos recursos tecnológicos meios que agregam possibilidades, tanto nos aspectos individuais quanto nos coletivos. Este estudo buscou identificar um perfil docente com foco na utilização de dispositivos digitais para o exercício de suas funções e aprimoramento das práticas pedagógicas. Para isso, foi aplicado um questionário para professores de uma rede municipal da região metropolitana de Porto Alegre. Dessa maneira, identificou-se o uso de tecnologias como possibilidade efetiva de romper com a solidão pedagógica por intermédio da criação de espaços de interação. O estudo aponta, ainda, a necessidade de estratégias formativas comporem políticas de formação docente, sendo acompanhadas de forma planejada.

PALAVRAS-CHAVE

formação continuada de professores; autoformação; trabalho colaborativo; tecnologias.

'Universidade Federal do Rio Grande do Sul, Porto Alegre, RS, Brasil.

"Universidade La Salle, Canoas, RS, Brasil. 


\title{
THE USE OF TECHNOLOGIES AS A TOOL FOR CONTINUED EDUCATION AND TEACHER SELF-FORMATION
}

\begin{abstract}
Teacher education is a lifelong process, which includes professional learning experiences that contribute to the quality of education. The continued education of teachers, contemplating self-forming and collaborative processes, finds resources in technological tools that add possibilities, both in individual and collective aspects. This study aims to identify a teaching profile, with a focus on professionals who use digital devices to exercise their functions and improve pedagogical practices. For this end, a questionnaire was applied to teachers in the municipal education system of the metropolitan area of Porto Alegre. In this way, the use of technologies was found to be an effective possibility to break pedagogical loneliness through the creation of spaces for interaction. The study also points out the need for education strategies to compose teacher education policies, being monitored in a planned manner.
\end{abstract}

\section{KEYWORDS}

teacher continued education; self-formation; collaborative work; technology.

\section{EL USO DE TECNOLOGÍAS COMO HERRAMIENTA PARA LA FORMACIÓN CONTINUA Y LA AUTO FORMACIÓN DE PROFESORES}

\section{RESUMEN}

La formación del profesorado es un proceso que dura toda la vida e incluye experiencias de aprendizaje profesional que contribuyen a la calidad de la educación. La formación continua de los docentes, contemplando los procesos de autoformación y colaboración, encuentra en los recursos tecnológicos medios que suman posibilidades, tanto en el aspecto individual como colectivo. El presente estudio buscó identificar un perfil docente con enfoque en el uso de dispositivos digitales para ejercer sus funciones y mejorar las prácticas pedagógicas. Para ello, se aplicó un cuestionario a docentes de una red municipal de la región metropolitana de Porto Alegre. Como resultado, se encontró el uso de tecnologías como una posibilidad efectiva de romper con la soledad pedagógica a través de la creación de espacios de interacción. El estudio también señala la necesidad de estrategias de formación para componer políticas de formación docente, siendo monitoreadas de manera planificada.

PALABRAS CLAVE

formación continua del profesorado; auto formación; trabajo colaborativo; tecnología. 


\section{INTRODUÇÃO}

Diante das evidentes transformações de várias ordens pelas quais passam o mundo contemporâneo, é fato que a educação precisa ser ressignificada e contextualizada, a fim de atender aos desafios que a ela se apresentam diariamente. Em estudo recente, Gatti (2017) observa que o cenário atual tem evidenciado características como competitividade, individualismo, multiculturalismo, novas linguagens e emergência de demandas por justiça social e equidade educacional. Esse contexto, no qual se efetiva o trabalho de professores e gestores educacionais e, consequentemente, a aprendizagem dos estudantes, é um espaço de tensões e impasses, em que a formação inicial dos docentes e as práticas da escola tradicional, na qual fomos formados, não conseguem corresponder às expectativas dos sujeitos e da sociedade como um todo e, por isso mesmo, "pedem novas compreensões para orientação de ações e relações interpessoais e educativas [...] e, sobretudo, novas posturas didáticas e formas diversificadas nas relações pedagógicas" (Gatti, 2017, p. 722).

A formação docente se caracteriza como um processo que ocorre durante toda a vida do professor ou professora, e abarca a totalidade de experiências de aprendizagem e de atividades intencionais para o benefício dos sujeitos, grupos ou escolas que contribuem para a qualidade da educação. Trata-se de um processo que pode realizar-se individual ou coletivamente, envolvendo a revisão, a renovação e a ampliação do compromisso dos docentes enquanto agentes da mudança (Ávalos, 2007). Para Ávalos (2007), aos processos formativos estão subjacentes polos de tensão, que dizem respeito tanto a elementos de cunho pessoal, como o compromisso individual do docente e a vontade de aprender, quanto a elementos externos, como as atividades de formação oferecidas e sua relação com os sistemas educativos.

Pesquisas realizadas na última década, dentre elas a de Gatti et al. (2019), dão conta de indicar a relevância da formação continuada de professores para a realização de um trabalho pedagógico mais consonante com as necessidades dos estudantes. No entanto, para além de pensar a formação continuada como um mecanismo capaz, prioritariamente, de suprir lacunas da formação inicial, nos propomos a pensar a formação continuada como algo inerente ao exercício da docência e que, por esse motivo, adquire um caráter de autoformação em que o profissional assume um papel de protagonismo no processo.

Warschauer (2005) assinala que a autoformação pertence a quem se forma e destaca a relevância dos novos instrumentos tecnológicos nesse processo, em que o ator principal, o professor, é o responsável pela construção de conhecimentos e sentidos produzidos durante esse processo permanente de formação. Alerta ainda para a diferença entre autoformação e autodidatismo, uma vez que os conhecimentos devem ser incorporados aos atos e valores e, portanto, devem estar articulados de sentido para o sujeito. Sendo assim, a autoformação seria um "trabalho sobre si mesmo"(Warschauer, 2005, p. 2), significando uma construção permanente do poder de agir, num movimento emancipatório com relação à dependência dos outros, mas em relação com esses. Os estudos de Canário (2006) apontam no mesmo sentido quando afirmam que a formação é um trabalho realizado, em grande medida, sobre 
si próprio, mas que, entretanto, ninguém se forma sozinho, reconhecendo a importância das interações formais e informais nos processos de formação.

Na perspectiva do que trazem Warschauer (2005) e Canário (2006), é possível destacar a recusa à individualidade como outro aspecto importante mediante a busca do caráter colaborativo da formação e da autoformação, desenvolvido essencialmente na dialética entre a condição individual e a condição coletiva (Josso, 2010; Vaillant, 2016; Nóvoa, 2002; 2009; 2017).

Considerando a formação continuada pela ótica desses dois importantes elementos citados, ou seja, da autoformação e da formação colaborativa, propomos a identificação de um perfil docente com foco na utilização de dispositivos digitais para o exercício de funções e aprimoramento das práticas pedagógicas. Com base nessas informações, é possível realizar uma reflexão acerca de como a tecnologia pode configurar um importante instrumento formativo/autoformativo, bem como um movimento que alia o caráter colaborativo ao uso das tecnologias para a formação docente. As tecnologias da informação e comunicação (TIC) têm assumido um importante papel enquanto recursos pedagógicos que podem potencializar os processos de ensino e de aprendizagem. Assim, o papel da tecnologia no desenvolvimento dos docentes pode aprimorar o processo de formação continuada, qualificando as práticas pedagógicas no contexto atual (Meirinhos, 2006). Tais elementos nos permitem pensar numa possibilidade de potencializar os processos de formação continuada dos docentes, qualificando, assim, suas práticas e as práticas da Escola como um todo.

Para dar conta dessas questões, apresentamos inicialmente elementos que tratam a questão da autoformação; em seguida, destacamos algumas reflexões sobre trabalho colaborativo e o uso de TIC. De forma complementar, utilizamos dados coletados por meio de questionário online, a fim de conhecer um pouco sobre o uso das tecnologias por parte dos docentes que atuam no Ensino Fundamental de um município da região metropolitana de Porto Alegre/RS. Finalmente, nos propomos a pensar esses elementos apresentados em correlação, destacando especialmente de que maneira a formação continuada pode ser potencializada a partir do uso das tecnologias pelos docentes.

\section{A AUTOFORMAÇÃO COMO POSSIBILIDADE DE FORMAÇÃO CONTINUADA}

Pensar a formação continuada hoje requer obrigatoriamente que desloquemos o nosso olhar das práticas e iniciativas formativas desenvolvidas em uma relação de exterioridade com os contextos de atuação profissional e foquemos nas ações concebidas e efetivadas desde o espaço da Escola, considerando, portanto, os desafios que se apresentam. Gatti e Barreto (2009) assinalam a necessidade de maior aderência da formação continuada à realidade das escolas, de modo que a ênfase nos problemas concretos, que emergem do cotidiano, constitua um fator de valorização pessoal e profissional, trazendo implícita a necessidade de uma ação integrada do coletivo de educadores na construção de novas alternativas de ação pedagógica. 
Gatti e Barreto (2009) apontam, dentre outras questões, que a formação continuada apresenta pouca sintonia com as necessidades e dificuldades dos professores e da escola, enfatizando que eles não participam das decisões acerca dos processos formativos a que são submetidos, e que a falta de acompanhamento e apoio sistemático da prática pedagógica dos professores acarreta em dificuldades em entender a relação entre o programa desenvolvido e suas ações no cotidiano escolar.

Nóvoa (2002) sinaliza na mesma perspectiva ao afirmar que a capacidade de desenvolvimento reflexivo por parte do professor deve servir de suporte ao conjunto de decisões que se apresentam no dia a dia da sala de aula e da escola, evidenciando novamente a relevância da autoformação, possibilitando tanto o direcionamento às necessidades individuais, quanto conferindo centralidade às trajetórias profissionais docentes. $\mathrm{O}$ fazer cotidiano assume, nesse contexto, um espaço privilegiado de formação e principalmente de autoformação, seja mediante processos de reflexão sobre as práticas pedagógicas, ou por meio da interação com colegas, obras e autores (Oliveira, 2008), a partir de um movimento autônomo e caracterizado pela iniciativa de mobilização individual ou coletiva.

Reconhecer o professor como sujeito de experiência e adulto que se forma implica admitir a aprendizagem como processo interno e que corresponde ao processo de sua autoconstrução como pessoa. A formação continuada, em especial, dirige-se a professores que acumulam experiência no exercício de sua profissão e que constroem e reconstroem práticas e teorias.

É preciso considerar, portanto, que o professor é portador de uma história de vida e uma experiência profissional que orienta o seu olhar e justifica determinados interesses e necessidades. Sendo assim, formar adultos implica produzir formação em colaboração, mobilizando recursos teóricos e práticos. A formação deixa de ser vista como modo de ensinar determinados conteúdos e como consumo de conhecimentos para ser assumida como possibilidade de crescimento, perspectiva de mudança e forma de resolução de problemas. (Cunha e Prado, 2010, p. 103)

Ao considerar os contextos de trabalho e atuação profissional como lócus da formação continuada (Nóvoa, 2009, 2019), confere-se cada vez mais um caráter de protagonismo aos docentes, evidenciando o valor das experiências formadoras carregadas de sentido e possibilitando um movimento que articula saber-fazer e conhecimentos com funcionalidade e significação. A autoformação ganha, assim, um especial destaque, uma vez que, pelo ângulo da aprendizagem, a experiência simboliza atitudes, comportamentos, pensamentos, saber-fazer e sentimentos que caracterizam uma subjetividade e identidades (Josso, 2010). Sendo assim, a autoformação, pertencendo ao sujeito, revela-se como um importante instrumento de qualificação das práticas, pois possibilita contemplar demandas e necessidades específicas do sujeito em formação. A autoformação, portanto, diz respeito aos processos buscados pelo professor de forma intencional, que colaboram para ampliar tanto os conhecimentos teóricos quanto práticos, e têm relação com a aprendizagem 
conjunta (Marcelo, 1999; Marcelo et al., 2016), ou seja, encontram na colaboração uma importante forma de efetivação.

A autoformação, nessa perspectiva, diz respeito tanto aos aspectos técnicos, pedagógicos, didáticos e metodológicos da profissão, quanto configura um processo de autoconstrução que se estabelece em todas as dimensões do sujeito. O professor, como trabalhador intelectual, se forma à medida que trabalha para o aperfeiçoamento de seu ofício: "para realizar suas próprias potencialidades, e quaisquer oportunidades que surjam em seu caminho, ele [o professor] constrói um caráter que tem como núcleo as qualidades do bom trabalhador" (Mills, 2009, p. 22).

\section{O TRABALHO COLABORATIVO COMO POSSIBILIDADE DE AUTOFORMAÇÃO DOCENTE}

O trabalho docente tem sido, historicamente, caracterizado pela individualidade (Diniz-Pereira, 2015), seja por questões estruturais ou por questões culturais, que têm definido a identidade docente a partir de uma concepção fragmentada e segmentada do trabalho, em contraponto ao emergente entendimento de coletividade, cada vez mais presente nas discussões contemporâneas em educação. A formação continuada, como elemento fundamental e indissociável de qualquer mudança educacional e inerente ao trabalho docente, não pode mais ser concebida na perspectiva do professor isolado, mas de um profissional que está inserido num corpo profissional e numa organização escolar (Nóvoa, 2002), pois o desenvolvimento profissional passa pela interação e colaboração entre os pares (Vaillant, 2016).

Considerando a necessária superação da forma individualizada do trabalho docente, fruto do isolamento provocado, em muito, pelo excesso de carga horária e a falta de tempos-espaços (Machado, 2013) para o desenvolvimento de um trabalho docente pautado pelo coletivo, iniciativas de trabalho docente colaborativo têm ganhado cada vez mais espaço, num movimento de recusa e resistência ao formato tradicional-histórico constituído sobre o que é ser escola e sobre o que é ser professor. Esse movimento se dá a partir do entendimento de que o isolamento a que está vinculado historicamente o trabalho docente em nada contribui no enfrentamento das situações latentes na escola e que desafiam os professores em seu cotidiano. A transformação desse cenário passa, necessariamente, por rupturas, que são fruto da ação organizada de pessoas e instituições profundamente vinculadas ao desejo de alterar radicalmente as situações dadas (Silva Júnior, 2015). Sendo assim, o comprometimento dos sujeitos envolvidos com novas formas de trabalho, investigação e cooperação é elemento fundamental para a criação de um modelo de trabalho e de formação colaborativa (Mizukami et al., 2002).

O trabalho colaborativo, portanto, mostra-se como uma estratégia fundamental de desenvolvimento profissional docente a partir de ações como estudo, compartilhamento de experiências, análise e investigação conjuntas sobre as práticas pedagógicas, seja em contexto institucional, vinculado a uma rede ou escola, ou em contexto social (Vaillant, 2016). 


\section{AS TECNOLOGIAS DE INFORMAÇÃO E COMUNICAÇÃO NA PERSPECTIVA DA APRENDIZAGEM DOCENTE COLABORATIVA}

A ascensão das TIC está interligando o mundo em redes globais, gerando enormes quantidades de comunidades virtuais (Castells, 1999). A informação não é um bem raro (Fayard, 2008), mas requer formas eficientes de construção de conhecimento a partir de si mesma. $\mathrm{O}$ acesso à informação nas últimas décadas assumiu um caráter mais democrático, acarretando uma mudança de comportamento na sociedade atual, uma vez que os recursos digitais permitem, hoje, a interação e a criação de novas linguagens que levem à reflexão e ao posicionamento crítico no processo de construção de conhecimento.

Para Castells (1999), as redes de informação ampliaram de forma significativa os relacionamentos econômicos, sociais e culturais. No entanto, no âmbito escolar, os docentes tendem a utilizá-las como recursos para os processos de ensino e aprendizagem numa forma de socializar o seu "saber" com os estudantes (Ferreira et al., 2016), de modo que estas redes são pouco utilizadas para o processo de formação continuada entre os próprios professores.

O fluxo constante de informação presente no dia a dia transformou a forma de comunicação entre os seres humanos, constituindo novos elos de relacionamento e estruturas sociais, de forma aberta, dinâmica, inovadora e equilibrada (Castells, 1999). Sendo assim, "a emergência de mecanismos inovadores e propositivos faz-se, então, necessária para o trabalho colaborativo em redes, de forma a potencializar a sua ação e ampliar o seu alcance a partir dos diferentes atores e setores envolvidos" (Gomes, Barbosa e Ferla, 2016, p. 201).

A inserção das TIC no ambiente escolar pode contribuir para expandir o acesso à informação e promover a criação de um movimento colaborativo que privilegie a construção do conhecimento, a comunicação e a formação continuada (Almeida, 2001), tornando-se, assim, um mecanismo inovador e propositivo.

$\mathrm{O}$ uso das tecnologias pela ótica da formação continuada, considerando as premissas da autoformação e da aprendizagem colaborativa, pode ser compreendido como uma importante ferramenta que possibilita e amplia as condições de interação e cooperação entre os docentes, favorecendo os processos formativos. No entanto, são necessárias mais evidências que suportem essa interdependência entre as TIC, a autoformação e a aprendizagem colaborativa.

Os conceitos teóricos apresentados até aqui servem de base para a elaboração de uma estratégia de pesquisa que busca a obtenção de dados relevantes para identificação de um perfil docente, com foco na utilização de dispositivos digitais para o exercício de funções e aprimoramento das práticas pedagógicas. Na próxima seção, serão delineados os procedimentos metodológicos que visam permitir a satisfação desse objetivo.

\section{METODOLOGIA}

A estratégia utilizada para este estudo foi a pesquisa de levantamento, uma vez que esta permite ao pesquisador obter dados primários, com a finalidade de 
apresentar uma descrição numérica de tendências, atitudes e opiniões de uma determinada população (Hair et al., 2005; Creswell, 2010).

A pesquisa de levantamento é muito apropriada para as ocasiões em que é necessário quantificar e mapear um grande número de elementos de uma população, de forma objetiva e direta (Gil, 2010; Yin, 2010; Klein et al., 2015).

Este estudo possui caráter descritivo, pois se propõe a descrever situações, fatos, opiniões e comportamentos, no contexto da população estudada (Lakatos e Marconi, 2009; Gil, 2010; Klein et al., 2015).

Foi aplicado, por meio da ferramenta Google Forms ${ }^{1}$, um questionário estruturado composto de 31 questões, contendo escalas de múltipla escolha, mistas e do tipo Likert de cinco pontos. Das questões aplicadas, 11 foram destinadas à caracterização da amostra, o que é extremamente importante na identificação do perfil dos docentes. As demais questões buscam medir seus conhecimentos, preferências e opiniões em relação à utilização de computadores e dispositivos digitais para o exercício de sua profissão.

Segundo Creswell (2010), o questionário é uma representação numérica de tendências, opiniões ou atitudes de uma determinada população, estudada mediante uma amostra que pode levar a uma generalização dos resultados.

O desenvolvimento do instrumento de pesquisa baseou-se no modelo TAM, Technology Acceptance Model (Davis, 1989). O modelo em questão pode explicar as causas determinantes da aceitação dos computadores por parte dos indivíduos. Outra característica importante desse modelo é a possibilidade de mapear o comportamento dos indivíduos frente a qualquer tipo de tecnologia, explicando os motivos de aceitação (ou não) destas por esses mesmos indivíduos.

A população estudada foi a de professores de uma rede municipal de ensino fundamental da região metropolitana de Porto Alegre/RS. Foi utilizada uma fórmula estatística proposta por Nique e Ladeira (2017) para determinar uma amostra mínima para generalização da população estudada, conforme a Equação 1.

$$
n=\frac{Z^{2} * p * q * N}{e^{2}(N-1)+Z^{2} * p * q}
$$

Em que:

$\mathrm{N}$ = a população total, que, nesse caso, é o número total de professores da rede de ensino pesquisada;

$Z=$ o intervalo de confiança, que será de $95 \%$ com desvio padrão de 1,96, muito utilizado nas pesquisas de levantamento (Nique e Ladeira, 2017);

e $=$ o erro amostral, que será de $5 \%$;

1 Ferramenta do Google que possibilita a criação de questionários e pesquisas online, permitindo o compartilhamento com pessoas que tenham acesso à internet. 
$\mathrm{p}=\mathrm{a}$ probabilidade de acontecer o evento, ou seja, na população de 2.000 professores $^{2}$ da rede, corresponde à chance do questionário ser respondido efetivamente por professores da rede.

É possível, embora seja improvável, que o questionário seja preenchido por um indivíduo que não seja professor da rede. Nesse caso, será utilizado um percentual de probabilidade que está ligado à margem de erro. $O$ valor de $p$ definido em $95 \%$ representa a probabilidade de acontecer o evento, ou seja, espera-se que $95 \%$ dos respondentes sejam professores da rede; o valor de q, definido em $5 \%$, representa a probabilidade de não acontecer o evento, ou seja, espera-se que $5 \%$ dos respondentes não sejam professores da rede.

Com base nos dados apresentados, temos a Equação 2:

$\mathrm{n}=\frac{1,96^{2} * 0,95^{*} 0,05^{*} 2000}{0,05^{2}(2000-1)+1,96^{2} * 0,95 * 0,05}$

$\mathrm{n}=70$ indivíduos

Com base nos dados apresentados, o resultado do cálculo amostral indicou uma necessidade mínima de 70 indivíduos para que a amostra possa ser considerada generalizável, representando com significância a população estudada.

Os questionários foram enviados por meio da ferramenta Google Forms, na segunda quinzena de maio de 2018. Foi obtida uma amostra de 143 respondentes, bem acima da condição imposta pelo cálculo amostral, o que garante maior fidedignidade e possibilidade de generalização dos resultados para toda a população estudada.

Para testar a confiabilidade do instrumento de pesquisa utilizado, no caso, o questionário, foi realizado o teste Alfa de Cronbach, que apresentou resultado de 0,811. O valor indicado está acima do recomendado pela literatura, que é de 0,7 (Hair Jr. et al., 2009), o que comprova a significância estatística da escala criada para o questionário. A normalidade dos dados foi verificada pela análise dos valores de curtose e assimetria (Hair Jr. et al., 2009). Segundo Kline (1998), os valores indicados para curtose devem ser abaixo de 10 , e os valores de assimetria correspondentes devem permanecer abaixo de 3 . Os valores obtidos nas questões formuladas ficaram dentro do recomendado pela literatura.

\section{ANÁLISE E DISCUSSÃO DOS DADOS}

\section{OS DOCENTES E O USO DE TECNOLOGIAS}

O avanço tecnológico tem alterado significativamente o cotidiano das pessoas. Essa alteração pode ser altamente positiva, ao mesmo tempo em que pode se

2 A Rede Municipal de Ensino tem pouco mais de 1.950 professores ativos. Para fins de cálculo amostral, o valor foi arredondado para 2.000 . 
tornar prejudicial em algumas situações. Uma das questões propostas indaga sobre a frequência na utilização de computadores e/ou dispositivos digitais no dia a dia. Como resultado, $75 \%$ dos respondentes indicaram utilizar sempre, $15 \%$ frequentemente, $8 \%$ ocasionalmente e $3 \%$ raramente, conforme apresentado no Gráfico 1.

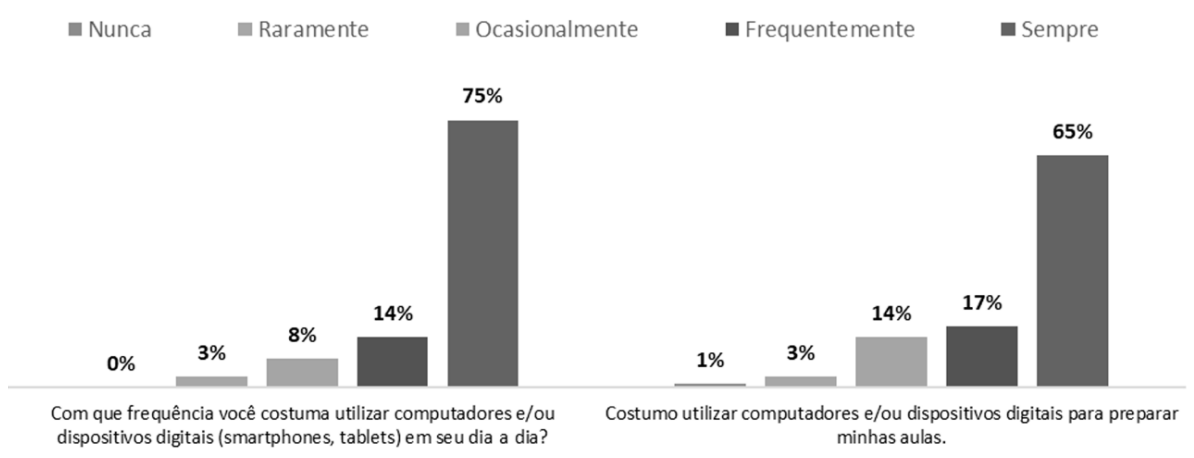

Gráfico 1 - Utilização de computadores e dispositivos digitais no dia a dia e no trabalho.

Esse resultado apresenta forte aderência dos professores pesquisados à tecnologia disponível para exercer as atividades cotidianas. A atividade humana, nos dias de hoje, não pode ser descrita, muito menos analisada, sem considerar o elemento da tecnologia como parte essencial das relações, de modo que, em alguns momentos, o ser humano torna-se refém dos artefatos tecnológicos, cuja utilização é componente fundamental na atualidade. Ao mesmo tempo em que a sociedade evoluiu a partir de um novo paradigma tecnológico, também se tornou dependente de uma modernização que remolda, de forma constante e inequívoca, as relações dos indivíduos para com o mundo ao seu redor. Sendo assim, é preciso inovar no sentido de responder às novas demandas do mundo moderno, necessitando avançar quanto às relações entre os sujeitos e o conhecimento (Canário, 2006; Sacristán, 2007; Porcheddu, Rezende e Bulgarelli, 2009), possibilitando novas formas de integrar as pessoas, facilitando o trabalho e considerando a tecnologia como uma importante ferramenta e não como um fim.

Com relação à utilização de computadores e/ou dispositivos digitais para preparação de aulas, $65 \%$ dos professores pesquisados afirmam utilizar sempre os recursos tecnológicos para este fim, 18\% indicaram utilizar frequentemente, $14 \%$ ocasionalmente, $3 \%$ raramente e apenas $1 \%$ afirmou não utilizar esses recursos. $\mathrm{O}$ fato de a ampla maioria dos professores indicar a utilização da tecnologia para preparar suas aulas pode designar vieses distintos. É fato que, com o passar do tempo, o indivíduo vai incorporando no seu cotidiano tudo aquilo que lhe é imposto ou que facilite suas atividades. É possível que essas duas questões estejam elencadas nesses padrões de resposta.

Com relação à percepção dos docentes quanto ao uso de computadores e dispositivos digitais (Gráfico 2), foi possível observar que 92\% consideram que computadores ou dispositivos digitais sempre ou frequentemente facilitam o seu 
trabalho, $7 \%$ consideram que ocasionalmente facilitam o seu trabalho e apenas $1 \%$ dos professores aponta que os computadores ou dispositivos móveis nunca facilitam seu trabalho. Os professores também foram questionados se o uso de computadores ou dispositivos móveis tornam o trabalho mais prazeroso (Gráfico 2).

Nunca $\quad$ Raramente $\quad$ Ocasionalmente $\quad$ Frequentemente Sempre

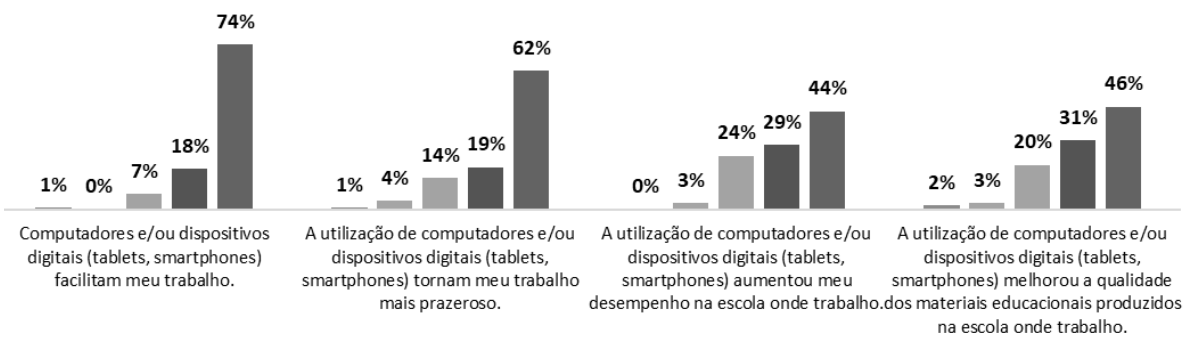

Gráfico 2 - Percepção dos docentes quanto ao uso de computadores e dispositivos digitais.

Quando questionados sobre a relação entre a utilização de computadores e/ou dispositivos digitais e o aumento do desempenho no trabalho, $44 \%$ consideram que isso ocorre sempre, $29 \%$ consideram que ocorre frequentemente, $24 \%$ declaram que contribui ocasionalmente e $3 \%$ apontam que raramente verificam esse aumento no rendimento. Com relação à qualificação dos materiais educacionais produzidos com a utilização de computadores e/ou dispositivos digitais, $77 \%$ estão entre os docentes que consideram que tal uso sempre ou frequentemente ocorre; $20 \%$ apontam que ocasionalmente há uma qualificação dos materiais produzidos; e $5 \%$ consideram que raramente ou nunca ocorre a melhora da qualidade destes materiais.

\section{O USO DE TECNOLOGIAS PARA A FORMAÇÃO CONTINUADA}

A questão seguinte trata sobre a utilização de computadores e dispositivos digitais para a formação continuada (Gráfico 3). Os professores foram questionados quanto ao uso desses recursos para buscar conteúdos acadêmicos ou profissionais de seu interesse; a maioria dos docentes (94\%) apontou que faz uso dessas ferramentas para este fim de forma recorrente (sempre/frequentemente); $4 \%$ fazem uso ocasionalmente e $2 \%$ apontam que nunca ou raramente as utilizam.

Ainda no mesmo item, questionou-se sobre a importância da internet e do uso de computadores para o processo de formação continuada dos professores. $92 \%$ dos docentes consideram que sempre ou frequentemente esses recursos desempenham um papel importante na formação continuada dos professores; $5 \%$ apontam que isso ocorre ocasionalmente e $5 \%$ consideram que raramente ou nunca a internet ou os computadores são importantes no processo de formação continuada. Ainda, ao questionar sobre o interesse em receber materiais sobre a área de atuação e atividade profissional, $90 \%$ dos respondentes apontam que sempre ou frequentemente tem esse 
Nunca $\quad$ Raramente $\quad$ Ocasionalmente Sequentemente

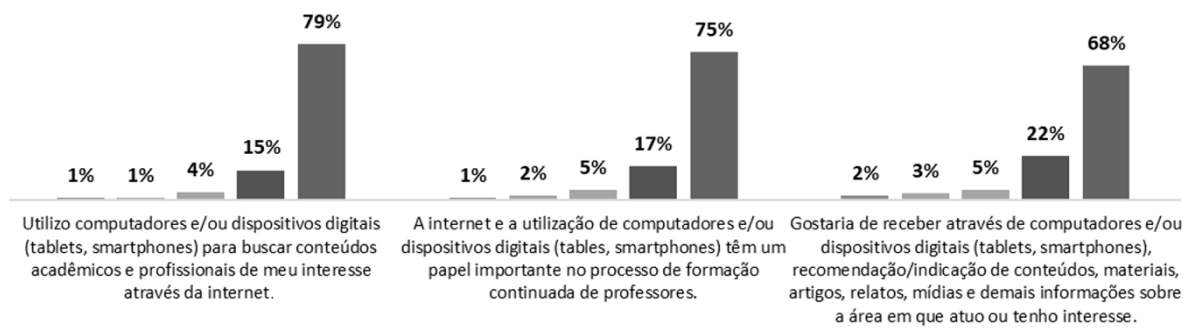

Gráfico 3 - Utilização de computadores e dispositivos digitais para a formação continuada.

interesse; $5 \%$ ocasionalmente têm esse interesse; e outros 5\% nunca ou raramente gostariam de receber materiais através de computadores ou dispositivos digitais.

Coerente com o contexto atual, a maior parte dos professores aponta uma grande familiaridade com o uso cotidiano das tecnologias, bem como expressa uma abertura a uma maior interação com essas ferramentas, valorizando o "potencial presente nas oportunidades de formação continuada, não apenas na perspectiva de desenvolvimento profissional, mas também com objetivos mais imediatos de melhoria de desempenho em sala de aula" (Gatti e Barreto, 2009, p. 221).

Os dados obtidos revelam uma adesão aos recursos e dispositivos tecnológicos por parte dos professores, corroborando o quanto esses recursos já se tornaram recorrentes e familiares ao cotidiano do exercício da prática docente. $O$ potencial desses recursos fica evidente nos dados apresentados; entretanto, a questão que se impõe como exigência para a continuidade da reflexão diz respeito a como lançar mão desse potencial e dessa familiaridade para a formação continuada sob a perspectiva autoformativa.

Nessa direção, dois elementos entram em cena: de um lado, o que a literatura no campo da formação de professores já consagrou como ponto de referência, concebendo a formação continuada como um continuum no desenvolvimento profissional docente, tendo o ponto de partida na formação inicial e dando continuidade a posteriori no exercício da profissão. Assim, esse continuum é marcado tanto pelas aprendizagens profissionais de caráter individual quanto pelas de caráter coletivo. É justamente esse caráter coletivo da formação que apontamos como o segundo elemento, e que tem sido enfatizado na literatura como uma exigência inerente ao aperfeiçoamento da ação profissional (Silva e Machado, 2018; Gatti et al., 2019).

É nessa segunda direção que entendemos a necessidade de pedagogizar o uso das tecnologias, de forma que os docentes possam ingressar com sua potencialidade nos processos formadores. Se os educadores já se encontram familiarizados com as TIC e fazem uso delas para suprir suas necessidades cotidianas de apoio ao exercício da docência (92\%), e, portanto, elas contribuem para um processo autoformativo, com ênfase no aspecto individual, a questão que se coloca é como lançar mão de propostas que agreguem igualmente o trabalho das interações coletivas. Aqui resi- 
de uma das limitações do levantamento realizado, que provoca a continuidade do trabalho de pesquisa.

Um dos modos de ampliar essa discussão, nesse momento, seria recorrer ao que pesquisadores têm apontado como resultado em seus trabalhos. Gabini e Diniz (2009), ao desenvolverem um trabalho formativo com um grupo de professores de química no estado de São Paulo, maximizando o uso de tecnologias na formação continuada, constatam que as tecnologias, quando planejadas e com intencionalidade, acabam por agregar e fortalecer elementos, tanto novos quanto já pertencentes às práticas convencionais dos educadores, ou seja, "os recursos da educação a distância tornaram-se elementos de ligação entre os encontros presenciais, mantendo vínculo no grupo e permitindo que as discussões não se restringissem a esses encontros que aconteceram mensalmente" (Gabini e Diniz, 2009, p. 7369).

Outro aspecto evidenciado pelos pesquisadores foi a emergência de oportunidades de participação, estimulada pelo formato virtual, para professores que comumente encontravam-se mais limitados pela produção do discurso oral. Para além disso, a pesquisa revelou que "foi possível estabelecer um espaço de troca de experiências, de potencialização de leituras e estudos e de reflexão crítica a respeito da prática docente, nesse conjunto presencial e virtual" (Gabini e Diniz, 2009, p. 7369). Finalmente, entendem que o estudo oportunizou o ingresso em um universo de compreensão acerca de como os professores podem ser mobilizados, por meio do uso de recursos tecnológicos, para maximizar seu processo formativo e autoformativo.

O presente estudo, pelos aspectos discutidos, defende a formação continuada como um espaço para o diálogo e para a partilha entre os professores, colaborando para que os mesmos tenham condições de analisar criticamente as suas práticas e buscar as formas mais adequadas de atuação, a partir dessa vivência coletiva. (Gabini e Diniz, 2009, p. 7370)

Tais elementos, verificados tanto na pesquisa realizada com profissionais da educação em município da região metropolitana de Porto Alegre quanto nos resultados obtidos por Gabini e Diniz (2009), são indicativos da potencialidade dos recursos tecnológicos para favorecer um movimento formativo e autoformativo dos professores, constituindo espaços para que as trocas e o compartilhamento ocorram, por meio da viabilização de espaços de interação.

\section{CONSIDERAÇÕES FINAIS}

Neste estudo, se colocou em destaque, para a construção da análise e reflexão, o potencial da formação continuada como processo autoformativo e colaborativo mediado pelos recursos tecnológicos. Desde a leitura consultada, partiu-se da premissa de que existe uma potencialidade nesses recursos, que podem se consolidar em elementos profícuos na capacitação docente, estimulando o trabalho de formação continuada, tanto no que se refere aos aspectos individuais do desenvolvimento profissional, quanto àquele que valoriza o conhecimento gerado pelas interações sociais e partilhas entre os pares. 
O estudo proposto objetivou identificar o perfil docente com foco na utilização de dispositivos digitais para o exercício de funções e aprimoramento das práticas pedagógicas. Os dados analisados revelaram uma familiaridade de grande parte dos docentes com os recursos tecnológicos, com ampla utilização destes no cotidiano. Entretanto, permanece o desafio de se potencializar o uso desses recursos para a finalidade formativa e autoformativa, ampliando as possibilidades de interação e de desenvolvimento profissional docente.

Pensar a educação e os processos formativos a partir dos contextos atuais é urgente e necessário. Estabelecer estratégias que favoreçam essa dinâmica constitui uma das possibilidades de qualificar a educação mediante ações concretas, que viabilizem que os movimentos formativo e autoformativo se constituam de forma intrínseca ao fazer docente. O estudo realizado confirma, considerando a familiaridade demonstrada pelos educadores (92\%), o potencial criativo e mediador dos recursos tecnológicos; entretanto, a criação de dispositivos formativos e autoformativos constitui um desafio de caráter material, institucional e simbólico, conferindo, especialmente aos gestores da educação, um papel central nesse processo, que envolve a definição de uma política de formação, planejamento e pressupostos teórico-pedagógicos claros na implementação de ações formativas.

Um dos desafios apontados pela produção na área diz respeito à superação do individualismo da prática docente e da própria carreira profissional. Os recursos tecnológicos e os espaços interativos virtuais têm potencialidade para mobilizar o rompimento da solidão profissional docente, o que nos impele a apostar na continuidade dos estudos, exercitando a criação de modos operacionais para tirar proveito daquilo que já está no cotidiano da ação docente.

Se, até pouco tempo atrás, os recursos tecnológicos eram pensados como mais uma alternativa a ser utilizada, estes, no momento atual, se mostram como uma das únicas possibilidades para efetivar os processos pedagógicos e de formação de professores em um contexto de pandemia. Nesse sentido, a necessidade de discussão das práticas pedagógicas mediadas pelos recursos tecnológicos nas escolas tem evidenciado uma urgência a ser enfrentada, uma vez que o trabalho pedagógico desenvolvido por meio do ensino remoto - em que pese o fato de estar atrelado à infraestrutura tecnológica e disponibilidade de acesso para quem precisa — já é uma realidade indissociável do ambiente escolar.

\section{REFERÊNCIAS}

ALMEIDA, M. E. B. Tecnologia de informação e comunicação na escola: aprendizagem e produção da escrita. São Paulo: PUC-SP, 2001. Disponível em: http:// www.eadconsultoria.com.br/matapoio/biblioteca/textos_pdf/texto24.pdf. Acesso em: 10 abr. 2018.

ÁVALOS, B. E1 desarrollo profesional continuo de los docentes: lo que nos dice la experiencia internacional y de la región latinoamericana. Revista Pensamiento Educativo, v. 41, n. 2, p. 77-99, 2007. 
CANÁRIO, R. A escola tem futuro? Das promessas às incertezas. Porto Alegre: Artmed, 2006.

CASTELLS, M. A era da informação: economia, sociedade e cultura. O poder da identidade. São Paulo: Paz e Terra, 1999.v. 1.

CRESWELL, J. W. Projeto de pesquisa: métodos qualitativo, quantitativo e misto. Porto Alegre: Bookman, 2010.

CUNHA, R. C. O. B.; PRADO, G. V.T. Formação centrada na escola, desenvolvimento pessoal e profissional de professores. Revista de Educação, PUC-Campinas, n. 28, p. 101-111, 2010. https://doi.org/10.24220/2318-0870v0n28a79

DAVIS, F. D. Perceived usefulness, perceived ease of use, and user acceptance of information technology. MIS Quarterly, v. 13, n. 3, p. 319-340, 1989. https://doi. org $/ 10.2307 / 249008$

DINIZ-PEREIRA, J. E. A construção do individualismo na profissão docente: como transcender as fronteiras tradicionais da identidade de professores? Revista de Educação, PUC-Campinas, v.20,n. 2,p. 127-142,2015. https://doi.org/10.24220/23180870v20n2a2993

FAYARD, P. A revolução gerencial das redes colaborativas. In: BALESTRIN, A.; VERSCHOORE, J. Redes de cooperação empresarial: estratégias de gestão na nova economia. Porto Alegre: Bookman, 2008. p. 9-12.

FERREIRA, G. E. et al. Configurações contemporâneas do mundo do trabalho, proatividades e redes de colaboração em saúde. In: GOMES, L. B.; BARBOSA, M. G.; FERLA, A. A. A educação permanente em saúde e as redes colaborativas: conexões para a produção de saberes e práticas. Porto Alegre: Rede Unida, 2016. p. 197-218.

GABINI, W. S.; DINIZ, R. E. S. Formação continuada de professores e novas tecnologias: integrando o presencial e o virtual. In: CONGRESSO ESTADUAL PAULISTA SOBRE FORMAÇÃO DE EDUCADORES, 10., 2009, Águas de Lindoia. Formação de professores e a prática docente: os dilemas contemporâneos... São Paulo: UNESP; PROGRAD, 2009. p. 7360-7371. Disponível em: http://hdl. handle.net/11449/139736. Acesso em: 30 mar. 2020. https://orcid.org/0000-00020192-3988

GATTI, B. A. Formação de professores, complexidade e trabalho docente. Diálogo Educacional, Curitiba,v. 17, n. 53, p. 721-737,2017. Disponível em: https://periodicos. pucpr.br/index.php/dialogoeducacional/article/viewFile/8429/17739. Acesso em: 13 abr. 2018. http://dx.doi.org/10.7213/1981-416X.17.052.AO01

GATTI, B. A.; BARRETO, E. S. S. (Coord.). Professores do Brasil: impasses e desafios. Brasília: Unesco, 2009. Disponível em: http://unesdoc.unesco.org/ images/0018/001846/184682por.pdf. Acesso em: 10 maio 2018.

GATTI, B. A. et al. Professores do Brasil: novos cenários de formação. Brasília: Unesco, 2019. Disponível em: http://www.unesco.org/new/pt/brasilia/about-this-office/singleview/news/professores_do_brasil_novos_cenarios_de_formacao/.Acesso em: 31 maio 2019.

GIL, A. C. Como elaborar projetos de pesquisa. São Paulo: Atlas, 2010. 
GOMES, L. B.; BARBOSA, M. G.; FERLA, A. A. A educação permanente em saúde e as redes colaborativas: conexões para a produção de saberes e práticas. Porto Alegre: Rede Unida, 2016.

HAIR JÚNIOR, J. F. et al. Fundamentos de métodos de pesquisa em administração. Porto Alegre: Bookman, 2005.

HAIR JÚNIOR, J. F. et al. Análise multivariada de dados. 6. ed. Porto Alegre: Bookman, 2009.

JOSSO, M.-C. Experiências de vida e formação. São Paulo: Paulus, 2010.

KLEIN, A. Z. et al. Metodologia de pesquisa em administração: uma abordagem prática. São Paulo: Atlas, 2015.

KLINE, R. B. Principle and practice of structural equation modeling. Nova York: The Guilford Press, 1998.

LAKATOS, E. M.; MARCONI, M. A. Fundamentos de metodologia científica: técnicas de pesquisa. 6 ed. São Paulo: Atlas, 2009.

MACHADO, J. A. A escola como espaço de formação continuada de professores: um estudo no contexto da Rede Municipal de Ensino de CANOAS-RS. Dissertação (Mestrado) - Programa de Pós-Graduação em Educação, Universidade La Salle, Canoas, 2013.

MARCELO, C. Formação de professores: Para uma mudança educativa. Porto: Porto, 1999.

MARCELO, C. et al. La innovación en la universidad: del Gatopardo al IPhone. Revista Gestión de la Innovación en Educación Superior, v. 1, n. 1, p. 29-57, 2016.

MEIRINHOS, M. F. A. Desenvolvimento profissional docente em ambientes colaborativos de aprendizagem a distância: estudo de caso no âmbito da formação contínua. Tese (Doutorado) - Universidade do Minho, Portugal, 2006.

MILLS, C.W. Sobre o artesanato intelectual e outros ensaios. Rio de Janeiro: Zahar, 2009. MIZUKAMI, M. G. N. et al. Escola e aprendizagem da docência: processos de investigação e formação. São Carlos: EdUFSCar, 2002.

NIQUE, W.; LADEIRA, W. Como fazer pesquisa de marketing: um guia prático para a realidade brasileira. São Paulo: Atlas, 2017.

NÓVOA, A. Formação de professores e trabalho pedagógico. Lisboa: Educa, 2002.

NÓVOA, A. Professores: imagens do futuro presente. Lisboa: Educa, 2009.

NÓVOA, A. Firmar a posição como professor, afirmar a profissão docente. Cadernos de Pesquisa, v. 47, n. 166, p. 1106-1133, 2017. Disponível em: https://dialnet. unirioja.es/servlet/articulo?codigo=6211666. Acesso em: 19 maio 2019. https://doi. org/10.1590/198053144843

NÓVOA, A. Os professores e a sua formação num tempo de metamorfose da escola. Educação \& Realidade, v. 44, n. 3, 2019. https://doi.org/10.1590/2175-623684910

OLIVEIRA, I. B. Criação curricular, autoformação e formação continuada no cotidiano escolar. In: FERRAÇO, C. E. (org.). Cotidiano escolar, formação de professores e currículo. São Paulo: Cortez, 2008. p. 42-63. 
PORCHEDDU, A.; REZENDE, N. L.; BULGARELLI, M. Zygmunt Bauman: entrevista sobre educação. Desafios pedagógicos e modernidade líquida. Cadernos de Pesquisa, v. 39, n. 137, p. 661-684, 2009. https://doi.org/10.1590/S010015742009000200016

SACRISTÁN, J. G.A educação que ainda é possível: ensaios sobre uma cultura para a educação. Porto Alegre: Artmed, 2007.

SILVA, G. F.; MACHADO, J. A. Saberes em diálogo: a construção de um programa de formação docente em uma rede municipal de ensino. Revista Iberoamericana de Educación, v. 77, n. 2, p. 95-114, 2018. Disponível em: https://rieoei.org/RIE/article/ view/3161/3978. Acesso em: 17 mar. 2020.

SILVA JÚNIOR, C. A. Construção de um espaço público de formação. In: SILVA JÚNIOR, C. A. et al. (org.). Por uma revolução no campo da formação de professores. São Paulo: Editora Unesp, 2015. p. 133-148.

VAILLANT, D. Trabajo colaborativo y nuevos escenarios para el desarrollo profesional docente. Docencia, n. 60, p. 6-13, 2016. Disponível em: https://ie.ort.edu.uy/ innovaportal/file/48902/1/trabajo-colaborativo-y-nuevos-escenarios-denise-vaillant. pdf. Acesso em: 16 maio 2018.

WARSCHAUER, C. As diferentes correntes de autoformação. Educação OnLine, 2005. Disponível em: https://331e03ee-3c3b-415f-be8d-7d48a2328167. filesusr.com/ugd/603c36_89c4041ad0c140b39714e12df7c83cc1.pdf. Acesso em: 11 jan. 2005.

YIN, R. K. Estudo de caso: planejamento e métodos. Porto Alegre: Bookman, 2010.

\section{SOBRE OS AUTORES}

Giovanni Bohm Machado é doutorando em informática na educação pela Universidade Federal do Rio Grande do Sul (UFRGS). Professor da Faculdade Luterana São Marcos (FLSM).

E-mail: giobohm@gmail.com

Juliana Aquino Machado é doutoranda em educação pela Universidade La Salle (UNILASALLE). Assessora Pedagógica da Prefeitura de Canoas/RS. E-mail: juliaqrs@gmail.com

Leandro Krug Wives é doutor em ciência da computação pela Universidade Federal do Rio Grande do Sul (UFRGS). Professor da mesma instituição.

E-mail: wives@inf.ufrgs.br

Gilberto Ferreira Da Silva é doutor em educação pela Universidade Federal do Rio Grande do Sul (UFRGS). Professor da Universidade La Salle (UNILASALLE).

E-mail: gilberto.ferreira65@gmail.com 
Conflitos de interesse: Os autores declaram que não possuem nenhum interesse comercial ou associativo que represente conflito de interesses em relação ao manuscrito.

Financiamento: $\mathrm{O}$ estudo não recebeu financiamento.

Contribuições dos autores: Escrita - Primeira Redação, Escrita - Revisão e Edição: Machado, G. B.; Machado, J. A.; Wives, L. K.; Silva, G. F.

Recebido em 31 de maio de 2020 Aprovado em 14 de outubro de 2020 